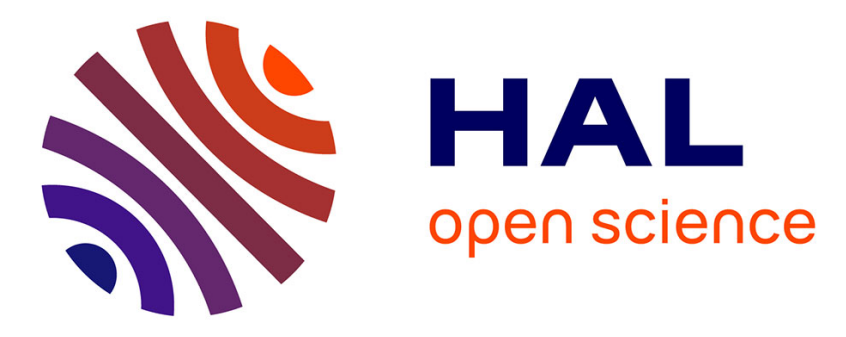

\title{
Usefulness Simulation of Design Concepts
}

Alborz Bekhradi, Bernard Yannou, Romain Farel, Benjamin Zimmer, Jeya Chandra

\section{To cite this version:}

Alborz Bekhradi, Bernard Yannou, Romain Farel, Benjamin Zimmer, Jeya Chandra. Usefulness Simulation of Design Concepts. Journal of Mechanical Design, 2015, special issue on "User Needs and Preferences in Design Engineering", pp.1-25. 10.1115/1.4030180 . hal-01152337

\section{HAL Id: hal-01152337 https://hal.science/hal-01152337}

Submitted on 15 May 2015

HAL is a multi-disciplinary open access archive for the deposit and dissemination of scientific research documents, whether they are published or not. The documents may come from teaching and research institutions in France or abroad, or from public or private research centers.
L'archive ouverte pluridisciplinaire HAL, est destinée au dépôt et à la diffusion de documents scientifiques de niveau recherche, publiés ou non, émanant des établissements d'enseignement et de recherche français ou étrangers, des laboratoires publics ou privés. 
Bekhradi A., Yannou B., Farel R., Zimmer B., Chandra J. (2015) 'Usefulness Simulation of Design Cancepts', Jaurna/ of Mechanical Design, nо. special issue on "User Needs and Preferences in Design Engineering", dai: 10.1115/1.4030180

\title{
Usefulness Simulation of Design Concepts
}

\author{
Alborz Bekhradi, Bernard Yannou, Romain Farel \\ Ecole Centrale Paris \\ Laboratoire Genie Industriel \\ Chatenay-Malabry, France \\ alborz.bekhradi@ecp.fr \\ bernard.yannou@ecp.fr \\ romain.farel@ecp.fr \\ Benjamin Zimmer \\ Silver Valley \\ 11, rue Pierre Rigaud \\ 94200 Ivry-sur-Seine, France \\ benjamin.zimmer@silvervalley.fr \\ Jeya Chandra \\ Penn State University \\ Harold and Inge Marcus Department of \\ Industrial and Manufacturing Engineering \\ 361 Leonhard Building \\ University Park, Pennsylvania 16802 USA \\ mic3@engr.psu.edu
}

\begin{abstract}
Usefulness, from the utilitarianism perspective, is the ability of a product or service to improve the well-being of humans and to minimize their suffering in different situations. In the case of the widespread issue of falls among the elderly, designing an adapted solution to is not an obvious task. The latter requires quantifying various usage scenarios. The usage scenarios, or segments, associated with elderly falls must be investigated to ensure that newly designed products and services are likely to bring essential health, social and economic values. Optimizing a design solution by considering the coverage of such usage segments extends the classical methods of design for market approaches. Starting from a disparate literature on elderly falls' issue, we have first built a usage scenarios space. Next, the usefulness and the coverage ability of three design solutions are evaluated over a tessellation of usage segments. In addition, the developed usage simulator is used to assess the potential of non or poorly-covered usage segments to deliver insightful information in order to truly be a need seeker in the front-end of innovation.
\end{abstract}

Keywords: design evaluation, usage simulation, usefulness, usage scenarios coverage, design performance simulation.

\section{NOMENCLATURE}

The following nomenclature list illustrates the main parameters and notations used in this paper:

$Y_{\text {real }} \quad$ Vector of real performance

$Y_{\text {sol. }} \quad$ Vector of design solution's performance 


$\begin{array}{ll}Y_{i d e a l} & \text { Vector of ideal performance } \\ S & \text { Total elderly population (65 years and older) } \\ F & \text { Total number of falls per year } \\ N & \text { Total number of registered falls in emergency departments per year } \\ H & \text { Total number of hospitalized elderly after a fall per year } \\ D & \text { Total number of deaths caused by falls among the elderly per year } \\ n & \text { Probability of falls per year and per person } \\ D F L E & \text { Number of Disability Free Life Expectancy years } \\ N Y M C & \text { Number of Years remaining to live with a Modified level of Comfort } \\ F C & \text { Financial Costs per year in euros } \\ F_{i} & \text { Usage variable } \\ f_{i, j} & \text { Usage modality } \\ s_{i, j} & \text { Size (in percentage) for variable } i \text { and modality } j \\ n_{i, j} & \text { Probability of falls per year and per person for variable } i \text { and modality } j \\ d_{i, j / j} \text { ' } & \text { Average relative probability of fall } \\ s c & \text { Index for usage scenario } \\ s_{s c} & \text { Size of usage scenario (in percentage) } \\ n_{s c} & \text { Probability of falls per year and per person for a given usage scenario } \\ \boldsymbol{h}_{i, j} & \text { Probability of hospitalization for the combinations of "Age“ and "Gender" } \\ & \text { modalities } \\ \Delta n o . & \text { Design solution's effectiveness (in percentage) } \\ \Delta U_{g l o b a l} & \text { Reduced probability of falls per usage scenario } \\ U P_{s c .} & \text { Global usefulness potential vector } \\ & \text { Usefulness potential per usage scenario }\end{array}$

\section{INTRODUCTION}

From the utilitarianism perspective [1], "usefulness" of a solution is defined as its ability to improve the well-being of humans and to minimize their suffering in different situations. According to Jeremy Bentham, the British philosopher of the $18^{\text {th }}$ and $19^{\text {th }}$ centuries, maximizing the overall well-being of sentient beings is equivalent to minimizing their suffering and thus, creating values for them [1]. Inspired by this statement and in the context of designing a product for a market, it is not trivial to determine which design solution is adequate for which suffering-oriented needs on the market, and to measure the usefulness of this solution.

Designing an adapted solution for a market requires verifying whether it adequately provides an answer to the existing needs of the target population. This task becomes trickier when one wants to design a solution for a widespread and multisituation usage issue involving an important part of the population. Furthermore, due to the lack of unified and reliable data, design decision-makers are not always able to quantify varied usage situations and thus to guarantee the success of their product on the market.

To better illustrate the above-mentioned statement, we have chosen to provide the example of accidental falls among the elderly. Indeed, a brief literature review in design engineering shows that no clear method exists to deal with these multiple and complex usage situations.

Accidental falls among the elderly of 65 years and above occur under varied contextual situations [2] and cause several bio-psycho-social consequences [3], leading to almost 5,000 deaths per year in the Metropolitan France, which is more than twice the number of deaths caused by car accidents. In addition, the emergency interventions and the hospitalizations are costly and the person's autonomy and life expectancy may 
decrease significantly as a result of a brutal fall. The economic overhead of fall-caused problems for the public services has notably increased during the last decades, and is continually amplifying, as the population is growing older [4].

To deal with this issue, several design solutions (products and services) have been developed. Figure 1 provides some examples of design solutions categorized into two types of product families: fall prevention products (e.g. light pathway to prevent nocturnal falls) on the one hand, and products designed to detect falls with an emergency alert system (e.g. watch or roundel) on the other. These are examples of design solutions aiming at offering innovative services to users, and thus conquering new market shares of the relevant French gerontechnology market.
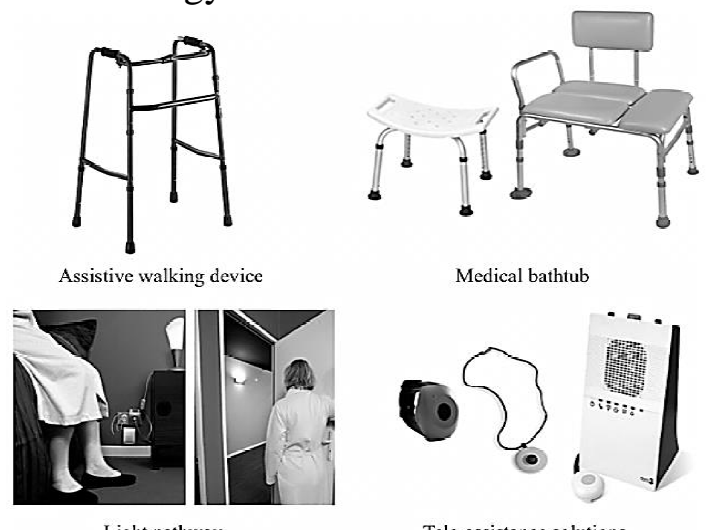

Light pathway

Tele-assistance solutions

Figure 1. Design solutions to prevent and alert elderly falls

However, these solutions do not seem to be meeting this objective, particularly due to the fact that the current gerontechnology market is still small and rather focused on specific niches. Moreover, the economic model of these products is intricate, insofar as the boundaries between care and welfare are narrow. Indeed, the purchase decision of customers is often prompted by the French social security system (through financial aids targeting specific products and services), as well as private insurance companies. In addition, most of the times, the purchasers of these solutions are not the elderly, but the health care institutions or the elderly's relatives.

In this context, the gerontechnology products, particularly those related to elderly falls, are not sufficiently user-oriented or usage-driven, and do not provide adequate responses to their needs. This is most probably due to the fact that existing evaluation methods of design solutions are not relevant, insofar as they do not fully focus on measuring how a product can meet the needs of users in multiple usage situations.

Yet, in the literature, design is defined as a structured process, not only consisting in the identification of problems and the development of new products, but also in the evaluation of user-focused solutions [5]. It is also commonly acknowledged that an accurate understanding of the multi-dimensional aspects of usage situations is necessary in the early stage of the design process to improve the perception of solution's performance [6]. Based on the experiences of design and engineering for patient safety $[5,7]$, as well as in inclusive design [8], it is recognized that effective usage integration into the design process can facilitate the delivery of products and services to users in a convenient, simple to use, and comfortable way. By contrast, ignoring the complexity of the usage situations, leads to designing solutions that are, at best, far less effective than 
they could be, particularly in the case of elderly falls. At worst, they are unjustifiably costly for the health care system and for elderly's relatives. Despite all this, the contribution of design innovation to improve user and usage understanding in the context of medical systems, such as in the case of falls among the elderly, is an area that remains rather unexplored.

The main objective behind this study is to develop a method aiming at properly evaluating the usefulness of an existing solution (usefulness being defined here as the ability of reducing suffering for users). This evaluation method aims at helping solution designers to determine whether existing design solutions sufficiently meet the needs of users in multiple usage segments.

The research approach adopted in this paper falls within a need seeker strategy, which is today one of the three innovation marketing strategies identified in the innovation management literature [9] (along with the market reader and technology driver strategies). Need seekers, such as Apple (US) and Dyson (UK), "make a point of directly engaging potential customers" in the design process, in order to generate new ideas. In other words, this method consists in developing new products based on the observation of end-users' needs. However, the need seeker strategy is not commonlyused in design literature. For instance, the methods for customer-needs and opportunity identification, developed by Ulrich and Eppinger [10], adopt a market reader approach. In this method, the generation of ideas results from the monitoring of markets, customers and competitors, as well as the creation of value through incremental innovations. Yet, we consider that the observation of users is more efficient to provide relevant solutions alleviating their suffering, rather than simply expecting them to express their needs.

Nevertheless, insofar as few research studies focus on the observation of endusers' suffering-oriented needs, there is a lack of quantification tools and methods to measure this suffering and to evaluate the performance of the existing design solutions in terms of their usefulness. Hence, a simulation method is presented in this paper to evaluate not only the usefulness of design solutions under varied usage situations, but also to identify the areas of user needs that are not satisfactorily covered by these solutions.

The present paper begins with a literature review, outlining on the one hand the evaluation methods of a design for a market, and analyzing the usage segmentations on the other. In a subsequent section, we describe our methodology of usage simulation for the widespread issue of elderly falls. Section 4 focuses on the definition of performance vectors. Then, we explain how the usage scenarios space is built (Section 5) and how a usage simulator allows predicting characteristics of usage scenarios (Section 6). In Section 7, we comment on the obtained results over the evaluation of design solutions for falls among the elderly. Finally, in Section 8, we identify the potential values to be created and used in the front-end of innovation.

\section{BACKGROUND AND RELATED WORKS}

\subsection{DESIGN EVALUATION IN THE CASE OF A WIDESPREAD USAGE ISSUE}

When one deals with a widespread usage issue, it is worth taking a deeper look into the design for market approaches, focusing particularly on their ability to evaluate a 
design solution. However, insofar as we exclude in this paper the question of users' choice (by specifying a value creating solution maximizing health, social and economic usefulness), it is not trivial to define an appropriate design evaluation methodology.

One of the traditional ways to assess the expected performance of a product or service is the design optimization approach, focusing on the customer's preferences and based on a functional analysis. This approach aims at optimizing a given design solution by developing the aggregated preference models and by minimizing the relative distance of the solution's performance from the Pareto frontier $[11,12]$. The necessary data for building the aggregation models are gathered by performing marketing surveys and design workshops over the users' expectations. However, Yannou et al. underline in [13] that design optimization remains a contestable method to evaluate a design solution to the extent that aggregating customers' preferences may distort the optimization results, given the variety of customers' preferences. Therefore, applying the classical design optimization method is not appropriate for the evaluation of a product with multi-usage situations.

Building a choice or market share prediction model represents another traditional way of evaluating a product designed for a given market. However, this approach is based on a tedious cross-sectional marketing investigation averaging the customer's preferences. In other words, human appraisal of a customer panel must take place to build the choice model by considering the Expected Utility Value Theory on the basis of Conjoint Analysis [14] or Choice Analysis [15-17]. Besides, the utility/choice or market share model does not seem to be adapted to radical innovation $[13,18,19]$, due to the fact that marketing attributes, which structure the customer questionnaires, focus mostly on solution features and are not user's need-oriented.

In this context, the identification of the appropriate methodology for modeling usage situations in the case of a widespread issue is essential. Modeling the usage contexts is an emerging research topic, which is mainly explored in $[20,21]$ by studying the product's usage context and by evaluating the uncertainty and variability of lifetime energy usages. In [20] a PGM (Probabilistic Graphical Modeling) approach is employed to demonstrate the influence of the usage context as a set of dependent factors. The latter research work is aligned with a new methodology, called design by usage coverage [13], aiming at evaluating a rather innovative design solution by analyzing how customer's real needs are satisfied (or covered). This method brings significant improvements to the evaluation of a design solution depending on varied usage situations in the case of a widespread issue.

The usage coverage simulations have already been applied to optimizing a jigsaw product family [22], where building of performance models is conditioned on modeling the space of usage scenarios based on screened usage representative variables. These simulations provide predictions on engineering performance of a product-service by quantifying feasible usage scenarios partially covered or not covered by this performance. These simulations result in a series of absolute usage coverage indicators (providing the usage scenarios space) and relative usage coverage indicators (referring to competing products for the same need category to be covered) (see Figure 2). 


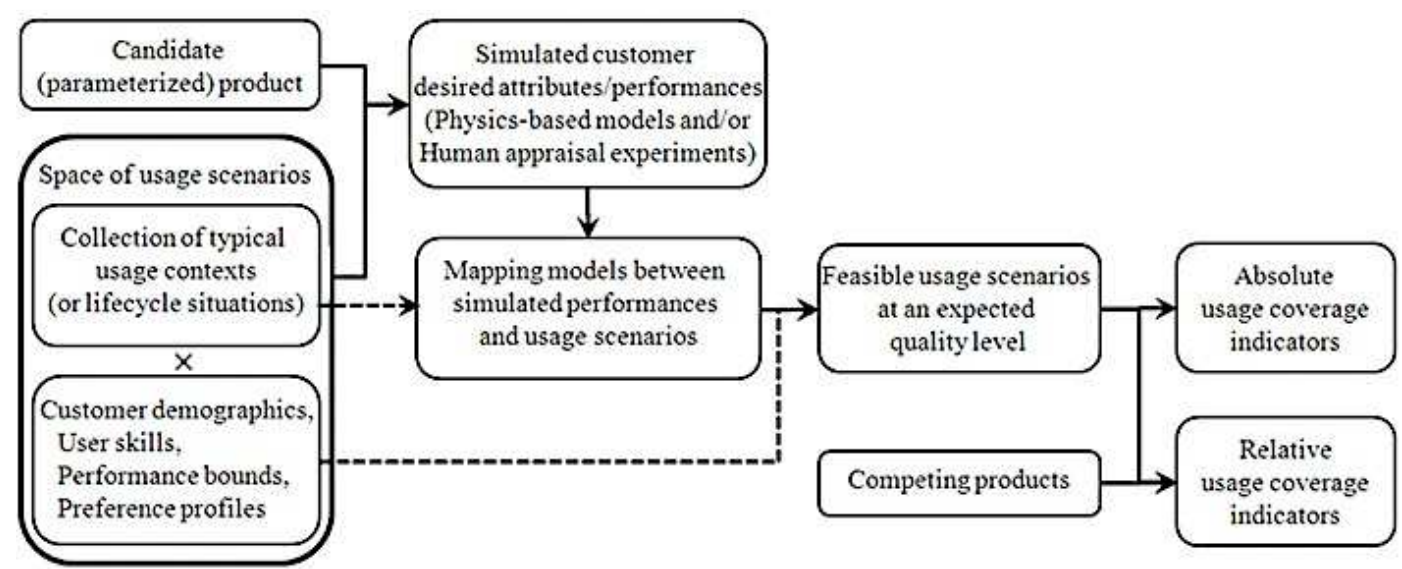

Figure 2. Design by usage coverage framework described in [13]

The assessment of absolute and relative usage coverage indicators provides decision-making elements to designers, enabling them to identify the partially-covered or orphan (i.e. not covered) usage segments. Based on the identified segments and their importance in terms of coverage, innovative insights for specifying a new product or service can be outlined [13]. Obviously, developing an adequate innovative design solution for the segments of the market where there is few or no solution will contribute to define wining strategies, and thus help industries to be more competitive on the market.

In summary, when designers face a widespread usage issue, it is not easy to evaluate the adequacy of the existing design solutions in terms of satisfying the needs and minimizing the suffering of users. Besides, it is not always an easy task to identify and quantify the non-covered or poorly-covered usage segments. We believe that the usage coverage simulations provide a relevant method to identify and measure these usage segments, by generating usage scenarios rather than maximizing absolute customer's preferences, which are often driven from tedious and sometimes unrealizable marketing surveys.

Nevertheless, in order to acquire a deeper understanding of multiple usage situations, it is necessary to analyze the existing methods regarding usage segmentation.

\subsection{USAGE SEGMENTATION}

The usage segmentation not only consists in identifying the preferences of the targeted users on the market, but also aims at apprehending their needs in different usage situations [19]. This statement is supported in a need seeker innovation process where investigating and quantifying usage segments contributes to improve the targeting of market segments, where there is a real need to be covered.

Statistical clustering methods such as k-means cluster analysis are frequently used in market segmentation by identifying homogeneous subsets of customers [23]. Conjoint Analysis [14] allows product and service providers to have a better perception of consumers' psychology, decision-making process and economic behavior. Other methods such as participatory design [24], broadly developed for IT products, and customerinteractive design (e.g. in the case of human-computer interface design), allow designers to become more acquainted with users' needs and behaviors. In the field of IT products, 
human interactions with computers and machines are observed in order to capture customers' contextual usage trends based on a contextual design process [25]. To refine the modeling of usage contexts or situations, the usage variables must be identified and selected according to a relevant investigation method.

To achieve this objective, Belk in [26] has put forward an S-O-R diagram (standing for Stimulus: choice possibilities for a given usage context, Organism: the customer and the Response: customer's choice). This diagram has been developed along with the identification of usage variables relating to users and usage contexts. Belk's method and marketing methods such as user personas [27] are based on a mere qualitative modeling of users' socio-demographic attributes and behavioral characteristics. Marketing questionnaires constitute the widely-employed tools for investigating consumers' characteristics in the form of human appraisals, helping to build the market and choice models $[15,16]$. However, in the case of a widespread usage issue, carrying out such marketing survey is costly and complex to perform.

The segmentation of a widespread issue, such as elderly falls, is a complicated and time-consuming task, due to the lack of reliable data and the complexity of investigating the elderly population through surveys. Thus, usage coverage simulations approach, advocated in [22], put forward the building of a usage scenarios space (or database), comprising both users' attributes and usage situational or contextual variables. A usage scenario represents a segment, which is, according to He et al. [18], defined as a combination of variables describing users' attributes and usage contexts. This combinatorial process for building usage scenarios is also used in the works of Philips [28] and Hoffmann et al. [29, 30]. A usage scenarios space is built from quantified data over the users' attributes and usage situations. The data are collected by studying the related literature, and validated by investigating domain-experts declaratives based on their knowledge of users' experiences and feedbacks from usage tests [31].

In this research, falls among the elderly are modeled by building a usage scenarios space, and by applying a different method than the one used for the optimization of jigsaw product family (see [22]). Elderly falls' usage variables are related not only to the socio-economic profile of the users, but also to a set of risk factors (such as etiological and behavioral causes). Besides, the design solutions aiming at preventing or reducing falls are used where there is a risk of falling, and not only when one decides to perform an action (as it is the case of jigsaw usage).

\section{USAGE COVERAGE METHODOLOGY FOR THE CASE OF ELDERLY FALLS}

The proposed research methodology is presented as a sequence of 5 steps, as shown in Figure 3. The first step focuses on defining a performance vector to be optimized. We first define an objective function, which consists in minimizing the diverse suffering points, needs, lacks of satisfaction and counter-performance that users can encounter. In the case of elderly falls, we only take into account miscellaneous suffering indicators, since the needs and dissatisfactions are not automatically expressed by elderly people. The counter-performance is not undertaken either, given that the design solutions are not systematically used by the elderly. The second methodological step concentrates on the building of a usage scenarios space by investigating the usage variables. Once the quality of the created database is validated throughout a data 
validation protocol, the third step consists in simulating the size of the usage scenarios, the probability of falls among the elderly as well as the real performance $\left(Y_{\text {real }}\right)$ (i.e. related to usage scenarios space without solution). In the fourth step, the usage scenariorelated performance of a design solution $\left(Y_{\text {sol. }}\right)$ is evaluated based on a mapping system through expert's declaratives. The comparison between the reference usage scenarios space (without a design solution) and the modified usage scenarios space (with a design solution) leads us to simulate the solution's usefulness by theoretically assuming that the latter would be used by everyone in any type of situation. The final step identifies the usage segments, which are not or poorly-covered by the existing design solutions, by comparing them to the ideal situation $\left(Y_{\text {ideal }}\right)$. The identification of these usage segments can reasonably be considered as valuable innovative insights for the designers to explore in creativity.

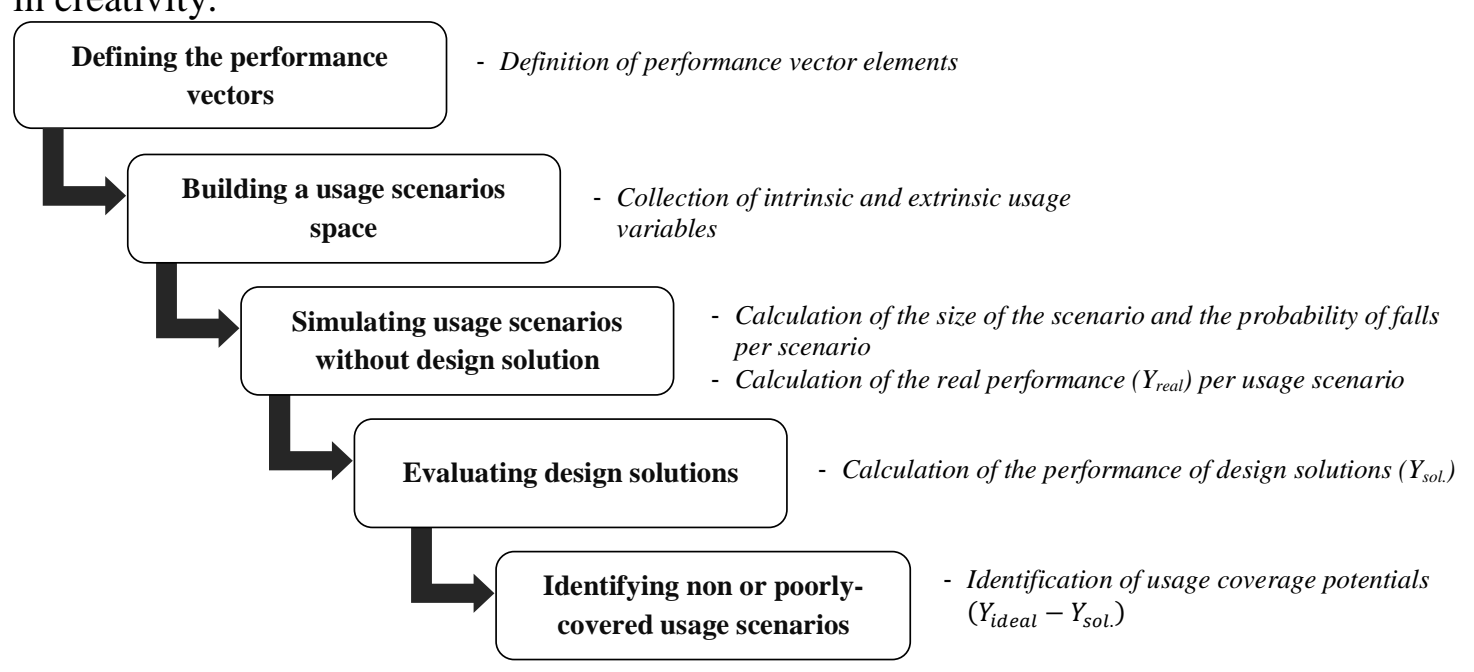

Figure 3. Usage coverage methodology for the widespread issue of elderly falls

Inspired by the TRIZ ideality principle [32, 33], the notion of ideal performance $\left(Y_{\text {ideal }}\right)$ is proposed to represent a utopian world where there are no suffering. In other words, there are no falls among the elderly in this world, or the issue of falls does not have any negative consequences. Based on this notion, the objective function is given by minimizing the sum of the difference between the vector of ideal performance ( $\left.Y_{\text {ideal }}\right)$ and the vector of exiting solution's performance $\left(Y_{\text {sol. }}\right)$ (see formula 1$)$.

$$
\operatorname{Min} \sum\left(Y_{\text {ideal }}-Y_{\text {sol. }}\right)
$$

On a usefulness scale (see Figure 4), optimizing the aforementioned objective function is the equivalent of minimizing the distance between the ideal performance and the existing solution's performance. On the same scale, the effectiveness of a product or service represents its ability to create value compared to the real performance, where no design solution is used or the existing design solutions are completely inefficient. 


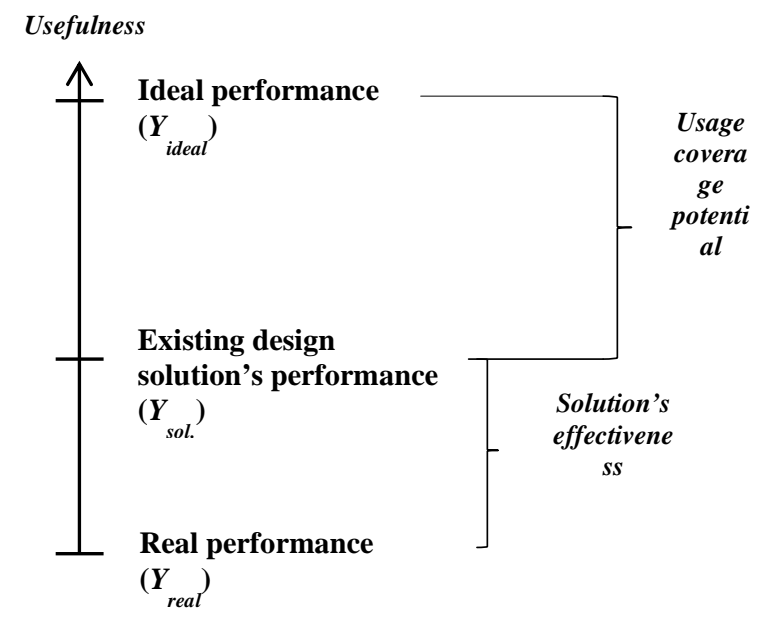

Figure 4. Representation of performance on a usefulness scale

In the following section, the 5 methodological steps are detailed for the case of elderly falls.

\section{DEFINING THE PERFORMANCE VECTORS}

Before detailing the performance vectors, providing a brief definition of elderly falls seems necessary. According to gerontology literature [34], an accidental fall is a sudden event, which breaks voluntarily, or involuntarily the postural balance of a subject (a person), and which leads the subject to "rest on the ground, floor or other lower level" [35]. Falls among the elderly are frequent, and due to a plethora of complex and multiple risk factors, they worsen with the age.

The target population of our study is the elderly population (aged 65 years and older) living in the Metropolitan France. In 2010, this population $(S)$ represented almost $17 \%$ of the total population (approximately 10.54 million). In 2050, according to [36], the elderly will represent one-third of the total French population. Approximately one out of three elderly living in the community falls at least once in a year $(F$ : total number of falls per year, i.e. 3.51 million elderly), according to gerontology literature [37-39]. The number of registered falls in emergency departments $(N)$ is 450,000 elderly per year. Consequently, we can infer the probability of falls per year and per person, as calculated by the formula 2 .

$$
n=\frac{N}{S}=0.04
$$

According to [40], the total number of hospitalizations $(H)$ caused by falls is 150,000 , and the total number of fall-related deaths $(D)$ is equal to 4,954 elderly per year according to [41].

The number of deaths $(D)$ as well as the number of hospitalizations $(H)$ constitutes the first suffering indicators of the performance vector. All suffering indicators of the performance vector must be defined as extensive, in order to be able to add them up per usage scenario, and thus to calculate the performance vector of all the usage scenarios space. 
In addition, one of the main consequences of falls among the elderly is the deterioration of their quality of life. To better understand the impact of falls on elderly's quality of life, life expectancy indicators must therefore be analyzed.

The DFLE designates the number of remaining "Healthy Life Years" (HLY) that a person, with a given age and gender expects to live, under the mortality conditions of a given period, and without being dependent on nursing or mobility aid for performing daily activities. Numerous statistical methods calculate the DFLE and the Total Life Expectancy ( $T L E)$, which is the total number of years that a person expects to live. The Sullivan method [42] calculates the TLE as well as DFLE and is the most relevant method applicable to our study. Indeed, not only are the input data available (i.e. mortality data and prevalence data over the population in healthy or unhealthy conditions), but it is also possible to calculate DFLE according to the age and gender ranges identified in this research (see Table 1). The $\triangle D F L E$ calculated in Figure 5, is equivalent to the loss in terms of years of DFLE caused by falls per usage scenario.

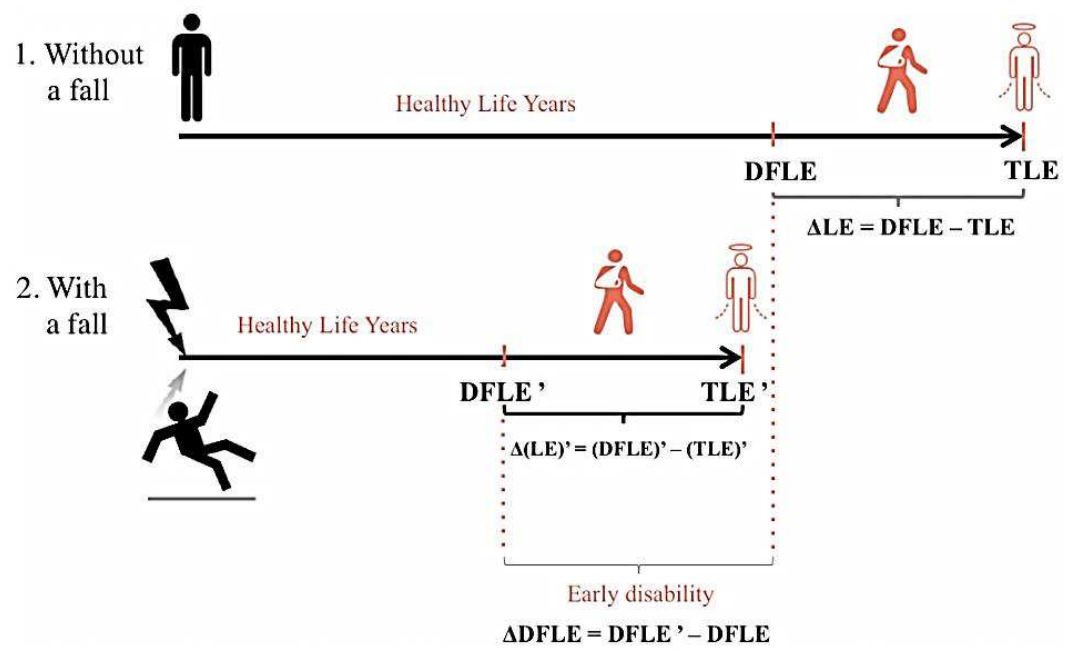

Figure 5. DFLE and TLE calculation for the case of falls among the elderly

The loss in terms of the DFLE due to a fall is given by the formula 3 . The equation 4 represents the Number of Years remaining to live with a Modified level of Comfort $(N Y M C)$ evaluating the number of years that an elderly lives in disability conditions.

$$
\begin{gathered}
\triangle D F L E=D F L E^{\prime}-D F L E \\
\text { Loss in } N Y M C=\left|\triangle L E^{\prime}\right|-|\triangle L E|
\end{gathered}
$$

Where the $\triangle L E$ is equal to the number of years that an elderly lives in disability condition in the "without a fall" case. The $\Delta L E^{\prime}$ represents the same difference for the "with a fall" case.

The financial costs $(F C)$ of falls among the elderly are substantial for the public health services. In France, a multitude of actors and organizations pays and/or receives monetary flows for the prevention of falls and for the reduction of their bio-psycho-social consequences. Given this complex structure of fall-related financial costs borne by numerous actors, we chose in this article to merely analyze the costs of emergency medical interventions and hospitalizations. The oldest available data dates back to 1993 and is equal to 1.34 billion euros. This cost has been re-estimated to almost 2 billion 
euros according to the rate of growth of the health expenditures from 1993 to 2010, provided in [43].

To summarize the above-mentioned elements, the performance vectors $\left(Y_{\text {real }}, Y_{\text {sol. }}, Y_{\text {innov. }}\right.$ and $\left.Y_{\text {ideal }}\right)$ are defined per usage scenario, based on 5 extensive suffering indicators $(D, H, D F L E, N Y M C$ and $F C$ ) (see matrix 5). The value of these indicators can be added up to assess the performance vector for the whole usage scenarios space.

$$
Y_{\text {real }}=\left(\begin{array}{c}
D \\
H \\
\text { loss in DFLE } \\
\text { loss in NYMC } \\
F C
\end{array}\right)
$$

The identified performance vectors must be first calculated per usage scenario, and then for the whole usage scenarios space. The building of a usage scenarios space is detailed in the following section.

\section{BUILDING A USAGE SCENARIOS SPACE}

\subsection{USAGE SCENARIOS VARIABLES AND CONSEQUENCES}

Due to the lack of a relevant and unified database relating to etiological and situational variables of falls, a significant investigation of the usage segments' characteristics has been carried out in this paper. This investigation study was twofolded: first, a literature review was conducted, based on the analysis of more than 60 medical publications; second, experts have been consulted to validate the selection of usage variables and the consequences of falling.

The gerontology literature shows that numerous variables can cause a fall (for instance authors in [44] have identified 400 uncategorized variables). In order to delimit the perimeter of usage variables, inspired by Belk's situational marketing researches [26, 45], we define usage variables as being relevant when they:

- indicate the profile of the target population (e.g. socio-demographic variables);

- cause a fall or impact its frequency in terms of probability (e.g. health problems);

- characterize usage contexts where a design solution makes a difference and therefore distinguishes these contexts from one another (e.g. indoor/outdoor activity or lighting conditions);

- influence directly or indirectly the consequences of a fall (e.g. age and health conditions).

In addition, all usage variables are considered in this study as being independent from another. For instance, the probability of falls for an elderly man is reported without taking into consideration his age or health conditions.

Based on the above-mentioned assumptions, two main categories of usage variables are distinguished: intrinsic variables (related to human attributes i.e. biological and socio-economic variables) and extrinsic variables (related to usage situations i.e. behavioral and environmental variables).

The review of more than 60 medical publications (such as $[46,47]$ ) has resulted in the identification of 31 intrinsic variables (including 12 health condition variables) and of extrinsic variables as well $\left(F_{i}\right)$. Here, we provide an exhaustive list of 12 health 
conditions usage variables in alphabetical order: Alzheimer's disease, Cerebral aging, Depression and Anxiety, Diabetes, Equilibrium problem and neurologic changes, Foot problem, Heart problem, Obesity problems, Osteoporosis in lower limb, Parkinson disease and sequel of brain injury, Under-nutrition and Vitamin D deficiency and Visual impairment (a detailed description of these variables is available in [48]). Each usage variable has two or several modalities, $\left(f_{i, j}\right)$ (72 modalities are identified in total). In [48], for each modality, a concise and clear definition is provided. Table 1 contains the most representative and commonly referenced usage variable addressed by gerontology and gerontechnology design studies (see [4, 46, 47]).

Table 1. Examples of usage variables and modalities

\begin{tabular}{|c|c|c|c|}
\hline Categories & Sub-categories & Usage variables & Modalities \\
\hline \multirow{4}{*}{ Intrinsic } & \multirow[b]{2}{*}{$\begin{array}{l}\text { Socio- } \\
\text { demographic }\end{array}$} & Gender $\left(\boldsymbol{F}_{1}\right)$ & $\begin{array}{l}\text { Male }\left(f_{1,1}\right) \\
\text { Female }\left(f_{1,2}\right)\end{array}$ \\
\hline & & $\operatorname{Age}\left(\boldsymbol{F}_{2}\right)$ & $\begin{array}{l}\text { 65- } 74\left(f_{2,1}\right) \\
75-84\left(f_{2,2}\right) \\
85 \text { and more }\left(f_{2,3}\right)\end{array}$ \\
\hline & \multirow{2}{*}{$\begin{array}{l}\text { Health } \\
\text { problems }\end{array}$} & Alzheimer's disease $\left(\boldsymbol{F}_{4}\right)$ & $\begin{array}{l}\operatorname{Yes}\left(f_{4,1}\right) \\
\operatorname{No}\left(f_{4,2}\right)\end{array}$ \\
\hline & & Diabetes $\left(\boldsymbol{F}_{\boldsymbol{6}}\right)$ & $\begin{array}{l}\operatorname{Yes}\left(f_{6,1}\right) \\
\operatorname{No}\left(f_{6,2}\right)\end{array}$ \\
\hline \multirow{4}{*}{ Extrinsic } & \multirow[b]{2}{*}{ Environment } & Place of living $\left(\boldsymbol{F}_{20}\right)$ & $\begin{array}{l}\text { Personal residence }\left(f_{20,1}\right) \\
\text { Institution }\left(f_{20,2}\right)\end{array}$ \\
\hline & & $\begin{array}{l}\text { Lighting conditions } \\
\left(\boldsymbol{F}_{19}\right)\end{array}$ & $\begin{array}{l}\text { Full enlightenment }\left(f_{19,1}\right) \\
\text { Low enlightenment }\left(f_{19,2}\right) \\
\text { Darkness }\left(f_{19,3}\right)\end{array}$ \\
\hline & \multirow{2}{*}{ Behavior } & $\begin{array}{l}\text { Indoor/outdoor activity } \\
\left(\boldsymbol{F}_{22}\right)\end{array}$ & $\begin{array}{l}\text { Always indoor }\left(f_{22,1}\right) \\
\text { Have outdoor activities }\left(f_{22,2}\right)\end{array}$ \\
\hline & & $\begin{array}{l}\text { Inappropriate foot wearing } \\
\left(\boldsymbol{F}_{26}\right)\end{array}$ & $\begin{array}{l}\text { Yes }\left(f_{26,1}\right) \\
\text { No }\left(f_{26,2}\right)\end{array}$ \\
\hline
\end{tabular}

For each usage modality, the size and the probability of falls per year and per person are calculated. The size of a modality $\left(s_{i, j}\right)$ represents its statistical proportion (or the number of observations) in the total elderly population. Modalities constituting a given variable are exclusive and discrete i.e. for each usage variable the whole population of French elderly people is totally distributed on its relative modalities (for instance, the size of $f_{1,1}, f_{1,2}$ is distributed as following: $s_{1,1}=42 \%$ and $s_{1,2}=58 \%$ ). The probability of falls per year and per person of a given modality $\left(n_{i, j}\right)$ is calculated by using the formula 6.

$$
n=\sum_{j=1}^{q} n_{i j} \cdot s_{i j}, \forall i
$$

Where $n$ is the total probability of falls per year and per person. The value of $\left(n_{i, j}\right)$ is provided by using the average relative probability of fall $\left(d_{i,\left(j / j^{\prime}\right)}=n_{i, j} / n_{i, j^{\prime}}\right)$. This variable represents the ratio between the probabilities of fall per year and per person of the modalities of a given usage variable $\left(j\right.$ and $\left.j^{\prime}\right)$. For instance, it has been 
acknowledged in medical literature that, in general, elderly women fall 1.7 times more than elderly men, i.e. $d_{1,(2 / 1)}=1.7$ [49]. Therefore, $n_{1,1}$ is calculated by the formula 7 .

$$
n_{1,1}=\frac{n}{s_{1,1}+1.7 \times s_{1,2}}
$$

After identifying the usage variables and modalities, a systematic review of the literature $[3,50,51]$ has resulted in the selection of a total of 27 consequences. These consequences are defined under two categories: 19 direct consequences (bio-psychosocial consequences related to a patient) and 8 indirect consequences (related to the use of healthcare services such as emergency services, for instance ambulance and hospital emergency department).

The basic probabilities of occurrence of the identified consequences are gathered in a matrix of consequences. In this matrix, we have assumed the probabilities for an "averaged reference fall", no matter which usage variables have caused a fall. In other words, a "fall" is equal to a "fall" regardless of its causing variables. This assumption is, of course, not true in reality but we are not attempting in this paper to model different contextual failure modes. Indeed, we merely intend to provide one reference failure mode for an averaged fall. From this averaged reference fall, we will allow some variations in terms of consequences on performance vectors.

\subsection{DATA QUALITY VALIDATION}

A data quality protocol must supervise the reliability and robustness of input data from the created pool of data. Data are collected, first of all, by reviewing the medical literature and fall-related references through statistical documents and fall prevention trials reports. Subsequently, missing data are explored by referring to the statistical data of different years and also to non-French data, which are adapted by analogy. In the case of non-univocal and missing data, we have consulted experts' declaratives in this domain. To achieve this goal, a set of data mining interviews have been conducted with experts in gerontology and gerontechnology, by using simple questionnaires. Thus, experts' knowledge of fall complications contributes to insure the exactitude of the selection of usage variables and consequences.

\section{SIMULATING USAGE SCENARIOS}

In engineering design literature, prediction models are developed by using statistical methods such as Bayesian inference. For example, Karandikar et al. have proposed an approach to simulate the remaining useful life of a given tool in machining industry [52]. Abbas et al. in [53] present a Bayesian methodology, which aims at providing an estimate of engineering products demand, thus supporting decision-making process, given the uncertainty inherent in the demand. These probabilistic simulations provide valuable information to designers allowing them to tune design parameters and thus to respond adequately to the market demands. The probabilistic simulations can also be used by performing queries from an intelligent database generating relevant test vectors in software testing domain (see for instance [54]). This database is supposed to capture and render chunks of reality weighed by their importance (like test vectors associated with a high probability to generate a software bug). In this paper, usage 
scenarios are therefore generated by learning from the distribution of the size of the segments as well as the probability of falls among the elderly.

An instance of usage scenario is generated by the combination of the modalities of the intrinsic and/or extrinsic variables, e.g. $S c_{1}=\left\{f_{1,1}, f_{2,3}\right\}=\{$ Male, 85 and more $\}$. The health condition can also be added to the previous example. For instance, $S c_{2}=$ $\left\{f_{1,1}, f_{2,3}, \boldsymbol{f}_{\mathbf{4 , 1}}\right\}=\{$ Male, 85 and more,Alzheimer $\}$. Therefore, usage scenarios are generated either by modifying the modalities of the same variable (e.g. by replacing "elderly man" by "elderly woman") or by adding or removing other modalities. The enumeration mechanism of the number of usage scenarios generated from a selection of usage variables can thus be complex, insofar as the number of selected modalities per usage variable is not always the same. In this paper, we focus only on the full instantiation of usage scenarios i.e. for a given selection of usage variables, generated usage scenarios contain one modality per usage variables among all of the selected variables. In this case, the enumeration will be easier and is given by the Cartesian product of the number of usage modalities. By taking $F_{1}$ and $F_{2}$ as examples, the total number of usage scenarios is equal to 6 given by the formula 8 .

$\{$ male, female $\} \times\{65-74,75-84,85$ and more $\}$

To calculate a given usage scenario's size and probability of falls per year and per person, the proportion of the target population is computed as being equal to the product of the relative size of the modalities composing this scenario. For instance, the size of $S c_{1}$ is given by formula 9 and the size of $S c_{2}$ is given by the formula 10.

$$
\begin{gathered}
s_{S c_{1}}=s_{1,1} \cdot s_{2,3} \\
s_{S c_{2}}=s_{1,1} \cdot s_{2,3} \cdot s_{4,1} .
\end{gathered}
$$

The probability of falls per year and per person for a usage scenario is calculated based on the Bayes' theorem. Given the assumption that probabilities of falls are considered as being independent from another, the formula 11 indicates the calculation of $P(\text { fall })_{S c_{2}}$.

$$
\begin{gathered}
P(\text { fall })_{S c_{2}}=P\left(\text { fall } \mid f_{1,1}, f_{2,3}, f_{4,1}\right) \\
=\frac{P\left(f_{1,1} \mid \text { fall }\right) \cdot P\left(f_{2,3} \mid \text { fall }\right) \cdot P\left(f_{4,1} \mid \text { fall }\right) \cdot P(\text { fall })}{P\left(f_{1,1}\right) \cdot P\left(f_{2,3}\right) \cdot P\left(f_{4,1}\right)}
\end{gathered}
$$

Where, $P(f a l l)=n$. Thus, the simplified equation of the formula 11 is given by the following formula:

$$
n_{S c_{2}}=\frac{n_{1,1} \cdot n_{2,3} \cdot n_{4,1}}{n^{2}}
$$

The probability of falls per year and per person represents the basis for the calculation of suffering indicators per usage scenario. The real performance vector of a usage scenarios space is calculated by adding up the real performance per usage scenario. The number of deaths per usage scenario is given by the product of the probability of falls $\left(n_{s c}\right)$ and the total number of deaths $(D)$ (see formula 13).

$$
\text { Number of deaths }=n_{s c} \times D
$$

The number of hospitalizations is calculated in a more complex way by calculating the product of the existing probabilities of hospitalization among the elderly population $\left(\boldsymbol{h}_{\boldsymbol{i}, j}\right)$, the probability of falls per usage scenario $\left(n_{s c}\right)$ and the total number of registered falls $(N)$ as shown by formula 14 . 
Number of hospitalization $=\boldsymbol{h}_{\boldsymbol{i}, \boldsymbol{j}} \times n_{s c} \times N$

The value of $\boldsymbol{h}_{\boldsymbol{i}, \boldsymbol{j}}$ is given by Table 2 , which represents the probability of hospitalization for the six possible combinations of "Age" and "Gender" modalities according to [55].

Table 2. Probability of hospitalization because of falls among the elderly

\begin{tabular}{|c|c|c|c|c|c|c|}
\hline Age $\times$ Gender & $\left\{\boldsymbol{f}_{1,1}, \boldsymbol{f}_{2,1}\right\}$ & $\left\{\boldsymbol{f}_{1,1}, \boldsymbol{f}_{2,2}\right\}$ & $\left\{\boldsymbol{f}_{1,1}, \boldsymbol{f}_{2,3}\right\}$ & $\left\{\boldsymbol{f}_{1,2}, \boldsymbol{f}_{2, \mathbf{1}}\right\}$ & $\left\{\boldsymbol{f}_{1,2}, \boldsymbol{f}_{2,2}\right\}$ & $\left\{\boldsymbol{f}_{1,2}, \boldsymbol{f}_{2,3}\right\}$ \\
\hline $\boldsymbol{h}_{i, j}$ & 0.32 & 0.44 & 0.24 & 0.2 & 0.43 & 0.37 \\
\hline
\end{tabular}

For the six usage scenarios generated from the combination of "Age" and "Gender" modalities (see Table 1), the loss in terms of DFLE years is calculated by equation 15 .

$$
\text { Loss in the DFLE }=\triangle D F L E \times n_{s c} \times D
$$

In this equation, the $\triangle D F L E$ represents the early disability due to a fall and is equal to the difference between the DFLE "with a fall" and the DFLE "without a fall". $S_{S c}$ represents the size of a usage scenario and $D$ is the total number of deaths per year, as we assume that an elderly could have survived with a number of the $|\triangle D F L E|$ years to live during a given year. The value of the loss in terms of the $N Y M C$ for a given usage scenario is calculated by equation 16 .

$$
\text { Loss in the NYMC }=\left|\Delta L E^{\prime}\right|-|\Delta L E| \times n_{s c} \times D
$$

Where, $\left(\left|\Delta L E^{\prime}\right|-|\Delta L E|\right)$ is related to the age and gender combination of the usage scenario, and represents the difference of unhealthy life years.

Given the extensive property of suffering indicators, for a usage scenarios space it is possible to evaluate the global performance by adding up the number of the DFLE years and the NYMC per usage scenario. Therefore, the global loss in terms of number of the DFLE years and NYMC are given by equations 17 and 18 .

$$
\begin{gathered}
\text { Total loss in DFLE }=\sum_{s c}\left[\Delta \boldsymbol{D F} \boldsymbol{L E} \times n_{s c} \times D\right] \\
\text { Total loss in } \boldsymbol{N Y} \boldsymbol{M C}=\sum_{s c}\left[\left|\Delta \boldsymbol{L} \boldsymbol{E}^{\prime}\right|-|\Delta \boldsymbol{L E}| \times n_{s c} \times D\right]
\end{gathered}
$$

The financial cost of hospitalizations because of falls for a usage scenario is calculated by the formula 19 , where the number of hospitalized elderly per usage scenario is multiplied by the average cost of hospitalization per person.

FC per usage scenario

$$
\begin{aligned}
& =N^{\circ} \text { of hospitalizations per usage scenario } \\
& \times\left(\frac{2 \times 10^{9}}{H}\right)
\end{aligned}
$$

In summary, given the extensive property of suffering indicators per usage scenario, the vector of real performance is obtained by the sum of real performance per usage $\left(Y_{\text {real }}\right)$, as given by matrix 20 .

$$
\sum_{\text {sc. }} Y_{\text {real }_{s c .}}=Y_{\text {real }}=\left[\begin{array}{c}
4,900 \text { Deaths } \\
150,915 \text { Hospitalizations } \\
15,967 \text { Loss in DFLE years } \\
14,535 \text { Loss in NYMC } \\
2 \times 10^{9} \mathrm{FC}
\end{array}\right]
$$


A summary Table 3 shows the different results of usage simulations for 2 usage scenarios composed of 4 usage variables.

Table 3. Alternative simulations on two usage scenarios

\begin{tabular}{cccccccc}
\hline \hline Usage scenario & $\boldsymbol{s}_{\boldsymbol{s c}}$ & $\boldsymbol{n}_{\boldsymbol{s c}}$ & $\begin{array}{c}\text { No. of } \\
\text { deaths }\end{array}$ & $\begin{array}{c}\text { No. } \\
\text { of } \\
\text { hospitalizations }\end{array}$ & $\begin{array}{c}\text { Loss in } \\
\text { DFLE } \\
\text { years }\end{array}$ & $\begin{array}{c}\text { Loss in } \\
\text { NYMC }\end{array}$ & $\begin{array}{c}\text { Financial } \\
\text { Costs }(\boldsymbol{F C})\end{array}$ \\
\hline & 0.03 & $8.823 \mathrm{E}-03$ & 169 & 6,688 & 525.41 & 459.94 & $3.03 \mathrm{E}+08$ \\
& 0.05 & $1.55 \mathrm{E}-02$ & 241 & 4,397 & $1,079.18$ & 908.65 & $5.83 \mathrm{E}+07$ \\
\hline \hline
\end{tabular}

The results of the above simulations represent the first examples of queries that can be formulated on our usage simulator. These quantitative results are useful for product designers insofar as they can accurately measure the importance of usage segments. Usage coverage simulations also allow designers to quantify the coverage capacity of their solutions and therefore to measure their performance by taking the usage situations and users attributes into consideration.

\section{EVALUATING DESIGN SOLUTIONS}

It appears to date that the question of the situational effectiveness of design solutions has not been sufficiently analyzed in France. There is therefore an important opportunity for measuring the coverage ability of design solutions over a tessellation of usage segments.

As shown in Table 4, three design solutions, selected from two categories of products, are analyzed in the following. However, further in our evaluations, the solutions are considered anonymous (Sol. 1, Sol. 2, Sol. 3) since the exact numerical data over the design solution's effectiveness are confidential.

Table 4. Alternative design solutions for the case of falls among the elderly

\begin{tabular}{|c|c|c|c|}
\hline $\begin{array}{c}\text { Product } \\
\text { family }\end{array}$ & Example & Description & Image \\
\hline $\begin{array}{c}\text { Fall } \\
\text { prevention }\end{array}$ & $\begin{array}{l}\text { Lighting } \\
\text { pathway }\end{array}$ & $\begin{array}{l}\text { A set of motion sensors detecting the } \\
\text { movement at the moment of getting up } \\
\text { from the bed by enlightening the path } \\
\text { between the bed and the restroom. The } \\
\text { solution is efficient during the night and } \\
\text { in the case of elderly with sleep } \\
\text { disorders. The solution is not efficient in } \\
\text { fully enlightened places. }\end{array}$ & \\
\hline $\begin{array}{l}\text { Fall } \\
\text { alert }\end{array}$ & $\begin{array}{l}\text { Tele- } \\
\text { assistance } \\
\text { roundel }\end{array}$ & $\begin{array}{l}\text { A pendant connected to a tele-assistance } \\
\text { platform service. In the case of fall, } \\
\text { elderly can alert emergency services by } \\
\text { pressing the button. The solution is not } \\
\text { efficient if the pendant is not worn or if } \\
\text { the elderly is not able to press the button. }\end{array}$ & \\
\hline $\begin{array}{c}\text { Fall } \\
\text { detection } \\
\text { and alert }\end{array}$ & $\begin{array}{l}\text { Tele- } \\
\text { assistance } \\
\text { bracelet and } \\
\text { service }\end{array}$ & $\begin{array}{l}\text { An intelligent watch connected to a tele- } \\
\text { assistance platform service via a modem- } \\
\text { box. The device can alert a fall manually } \\
\text { or automatically based on a fuzzy logic } \\
\text { calculation. The solution is not efficient } \\
\text { if falls are not "sharp". }\end{array}$ & \\
\hline
\end{tabular}


A design parameter measuring the effectiveness $(e)$ of a given design solution is defined as the ratio of the reduced probability of falls per usage scenario $(\Delta n o$.$) and the$ probability of falls per usage scenario $\left(n o_{s c}\right)$, as calculated by the formula 21 .

$$
e_{\text {sol.sc. }}=\frac{\Delta n o \cdot s c .}{n o \cdot s c \text {. }}
$$

This effectiveness of a product or service represents its ability to reduce the probability of falls and thus the bio-psycho-social consequences of falling among the elderly. However, the effectiveness can also be characterized by the mitigation of consequences of falling with the same probability of falls, for instance in the case of a hip inflatable protection belt [56].

The value of this parameter can be calculated by performing an exhaustive experimentation or fall trials. However, the latters are costly and not easy to implement. Therefore, a set of experts' declaratives is being used to assess the value of $e_{\text {sol }}$. per usage scenario. The declaratives of experts (here, gerontechnology experts including design solution providers) per usage scenario are registered in the form of classifiable rules by choosing usage variables and modalities. Error and trial heuristic form based on "If, Then" declaratives [57] are presented in Table 5. Experts classify these declaratives in order of priority. Furthermore, the stated effectiveness can be formulated in terms of the influence of the design solution on the "probability of falls" and also in terms of "the time it takes to provide assistance", as we are dealing with tele-assistance products and services as well. Matching the design solutions with the usage scenarios is realized by $a d$ hoc queries, that are applied to usage simulations according to designers or marketers claims, including AND, OR and NOT combinations of the simple predicate-like usage scenarios as evoked in Table 5.

Table 5. Experts' declaratives for $\mathbf{3}$ design solutions

\begin{tabular}{|c|c|c|}
\hline Sol. 1 & Sol. 2 & Sol. 3 \\
\hline $\begin{array}{l}\text { If }((\text { Gender is Male })) \text { Then } \\
\text { (Efficiency is } 10 \%)\end{array}$ & $\begin{array}{l}\text { If }((\text { Gender is Male })) \text { Then } \\
\text { (Efficiency is } 9 \%)\end{array}$ & $\begin{array}{l}\text { If }((\text { Gender is Male })) \text { Then } \\
\text { (Efficiency is } 8 \%)\end{array}$ \\
\hline $\begin{array}{l}\text { If ((Gender is Female)) Then } \\
\text { (Efficiency is } 15 \%)\end{array}$ & $\begin{array}{l}\text { If ((Gender is Female })) \text { Then } \\
\text { (Efficiency is } 10 \%)\end{array}$ & $\begin{array}{l}\text { If }((\text { Gender is Female })) \text { Then } \\
\text { (Efficiency is } 10 \%)\end{array}$ \\
\hline $\begin{array}{l}\text { If ((Age is } 75-84)) \text { Then } \\
\text { (Efficiency is } 20 \%)\end{array}$ & $\begin{array}{l}\text { If ((Heart problem is Yes)) Then } \\
\text { (Efficiency is } 20 \%)\end{array}$ & $\begin{array}{l}\text { If ((Alzheimer's } \\
\text { disease is Yes)) Then } \\
\text { (Efficiency is 10\%) }\end{array}$ \\
\hline $\begin{array}{l}\text { If ((Place of living is } \\
\text { Institutionalized)) } \\
\text { Then (Efficiency is 20\%) }\end{array}$ & $\begin{array}{l}\text { If ((Heart problem is No)) Then } \\
\text { (Efficiency is } 10 \%)\end{array}$ & $\begin{array}{l}\text { If ((Alzheimer's } \\
\text { disease is No)) Then } \\
\text { (Efficiency is } 8 \% \text { ) }\end{array}$ \\
\hline $\begin{array}{l}\text { If ((Age is } 75- \\
\text { 84) AND (Gender is Female) } \\
\text { AND (Place of living is Personal } \\
\text { residence)) Then (Efficiency is 15\%) }\end{array}$ & $\begin{array}{l}\text { If ((Gender is Female) AND (Place } \\
\text { of living is Institutionalized)) Then } \\
\text { (Efficiency is } 15 \% \text { ) }\end{array}$ & $\begin{array}{l}\text { If ((Lighting condition } \\
\text { is Darkness)) Then } \\
\text { (Efficiency is 30\%) }\end{array}$ \\
\hline
\end{tabular}

Subsequently an expert system algorithm verifies the exactitude of the declarations by processing all of the declaratives as per priority basis. For each declarative, the algorithm finds the elementary usage scenarios, which are affected by the rule. It then calculates the value of the total $\Delta n_{s_{s c}}$ for those affected scenarios. If the sum of $\Delta n o o_{s c}$ is the same as that of $\Delta n o_{s c}$ as per declarative (calculated from 
multiplying the efficiency with the total probability of falls for those scenario), then the program proceeds to the next declarative. If it is different, then the program checks whether the $\Delta n o_{s c}$ of the affected scenarios are modifiable or not. If so, then the value of $\Delta n o_{s c}$ will be changed as per the declarative and the program goes back to the beginning to check the validity of other declaratives with higher priority.

The vector of design solution's performance is given by the sum of the difference between the real performance per usage scenario $\left(Y_{\text {real }}\right)$ of the whole reference usage scenarios space without solution, and the new performance of the usage scenarios space with solution $\left(e_{\text {sol.sc. }} . Y_{\text {real }_{s c}}\right)$ (see formula 22$)$.

$$
Y_{\text {sol. }}=\sum_{\text {sc. }} Y_{\text {real }}\left(1-e_{\text {sol. }} \text { sc. }\right)
$$

For the three studied design solutions, as described in Table 4, solutions' performance is based on experts' declaratives (see Table 5) and solutions' real performance are compared over a usefulness scale illustrated by Figure 6 . The numerical values of simulations are normalized into the percentage of usefulness in order to make the solutions comparable.

The compared solutions are presented in an anonymous way due to the necessary confidentiality of the analyzed industrial data. These products or services are competitive and cover partially the usage segments. The solution 1 is more effective in this usage scenarios space in terms of reducing number of deaths by $9 \%$ and the number of hospitalizations by $15 \%$. If for a given population the suffering indicators were weighted, it would have then been possible to determine which one of the compared solutions is globally more adequate, with a relative higher potential of capturing market shares.

Given the variability of usage scenarios, covering the whole usage scenarios space does not appear feasible for only one product or service or a mere family of products. More often, the most efficient solution (reaching the ideal performance) in the whole usage scenarios space is not necessarily the most easy-to-access and affordable one for users. For instance, a permanent nursing caring solution at the elderly's place of living can significantly minimize the risk of falling and its consequences, but this solution is not available/affordable for everyone.

In Figure 6, the zone of non or poorly-covered usage scenarios by the existing design solutions can be identified, as we will see in the following section.

\section{IDENTIFYING NON OR POORLY-COVERED USAGE SEGMENTS}

The distance between the existing design solution's performance and the ideal performance constitutes an important value to be created, generating profitability for customers (new services and usefulness) as well as for industrial actors (new benefits and businesses). Hence, usage coverage simulations contribute to bringing usefulness and profitability evidences [6] from the front-end of innovation towards the process of maturity of evolving product or service concept, thus guarantying its success on the market.

The surface between the ideal performance and the existing design solutions' performance (as depicted in Figure 6) represents the potential of usage coverage, or the areas of suffering that are not covered by the existing design solutions (see Figure 4). 


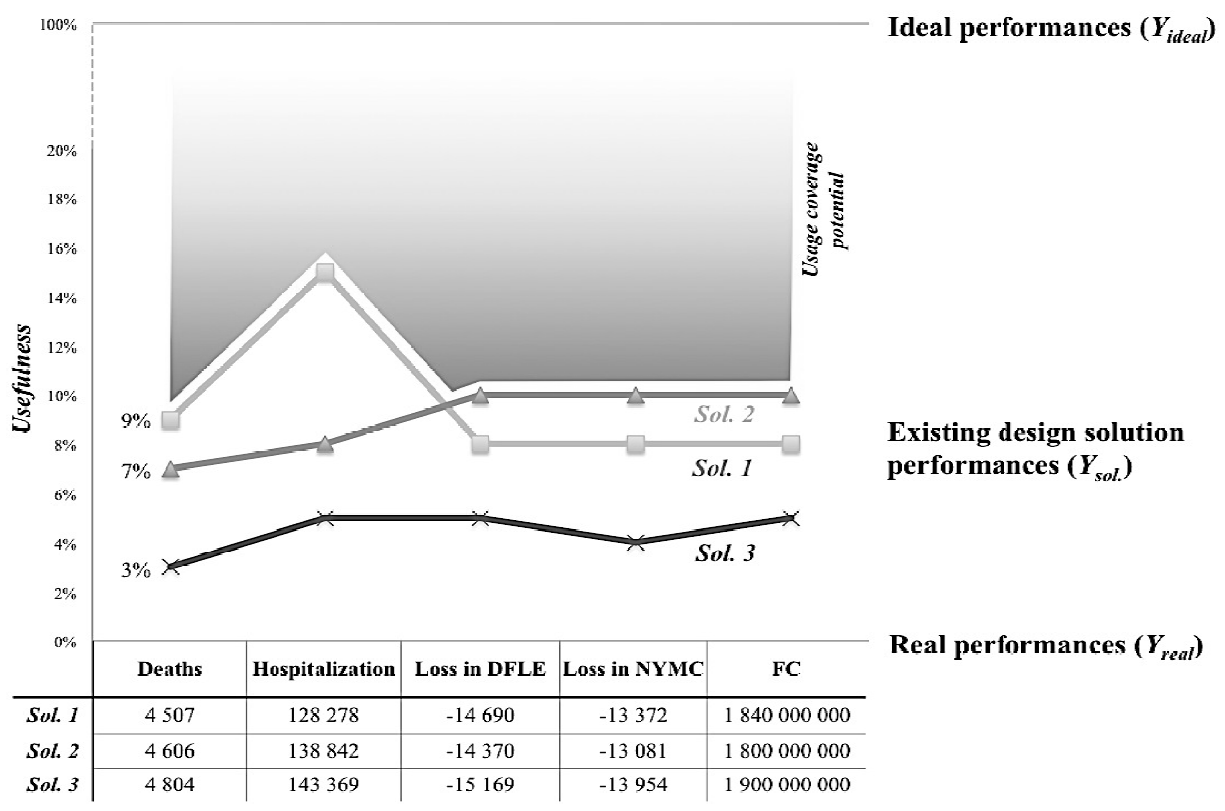

Figure 6. Identification of the usage coverage potential

This surface representing the potential of usage coverage is given by the global usefulness potential vector The vector is calculated by the ratio between the difference of the ideal performance vector with the Pareto frontier, characterized by , and the global usefulness creation, i.e. (see formula 23).

The potential usage scenarios to be covered must be explored and quantified somewhere in this surface. Our usage simulations enable the identification of the usage scenarios with the maximum usefulness potential per usage scenario . The usefulness potential is a ratio between real performance vector per usage scenario and the averaged claimed efficiency of the existing design solution in the same usage scenario. In other words, despite the seriousness of suffering indicators in these usage scenarios, the existing design solutions are not globally efficient. An alternative comparison is done between and (cf. Section 6). The equations number 24 and 25 shows the usefulness potential of the analyzed scenarios.

For the whole usage scenarios space and for the three mentioned design solutions, these simulations can be demonstrated through a case study. For the sake of simplicity, a set of 4 usage variables ("Age“, "Gender", "Alzheimer's Disease" and "Place of Living") is selected (see Table 1). A whole instantiation of the usage scenarios resulted in the generation of 24 usage scenarios, with each usage scenario composed of 4 modalities. The maximum value of is obtained by the usage scenario characterizing elderly 
women of 85 years and older who suffer from Alzheimer's disease, and who live in their personal residence $\left(U P_{s c \max }=\left\{f_{1,2}, f_{2,3}, f_{4,1}, f_{20,1}\right\}\right)$. The usefulness potential for the usage scenarios relating to elderly men is obtained by the usage scenario of elderly men, aged between 65 years and 74 years old who do not suffer from Alzheimer's disease, and who live in their personal residence $\left(U P_{s c m e n}=\left\{f_{1,1}, f_{2,1}, f_{4,2}, f_{20,1}\right\}\right)$. These simulations can bring useful innovative insights to solution designer looking persistently for innovative ideas in their front-end innovation process.

In addition to these simulations, we carry out an analysis of modality sensitivity by applying a Principle Components Analysis (PCA) over the reported data on our usage simulator's database. In this model, the probabilities of registered falls per year $\left(n_{i j}\right)$ of usage scenarios are considered as dependent, while the modalities composing each instance of usage scenarios are considered as independent. Once the non-existence of the collinearity is verified (according to Pearson correlation matrix), the choice of PCA method is confirmed. This step presets the correlations across the externalizing usage variables used in PCA. Eigenvalues are computed in a subsequent step, where, excluding the first component $\left(n_{i j}\right), 3$ other components ("female", "75 to 84 years" and "85 years and older" modalities) are extracted, as they represent altogether almost $90 \%$ of the total variance with an eigenvalue equal to or greater than 1.0 (according to Kaiser rule). The main reason of this extraction is that components must have variance at least as large as the dependent component. Various statistical analyses are possible in order to retain the most explicative components, which we will not detail further in this study. A Parallel Analysis (PA) indicates that two components (i.e. usage variables) should be retained, which are "female" and "85 years and older" modalities.

\section{DISCUSSION AND FUTURE RESEARCHES}

The results of our simulations on the evaluation of 5 product and/or services developed by French industries have been communicated (on an individual and confidential basis) to the industrial and institutional stakeholders who have financially supported this research.

Our ongoing research will focus on providing more accurate information on the usefulness potentials of value creation by specifying usage scenarios for which the suffering indicators are critical and for which health, social and economic essential values must be created. The specification of usage scenarios will be performed by quantifying value buckets based on a DSM tool as used in [58]. Hence, we will provide recommendations on the specifications of an innovative solution in the sense of the blue ocean strategy approach [59]. The automatized simulator is currently in a beta test phase and is available online for industrial and institutional actors.

The usage coverage model is extendable to a widespread issue if the expert's declaratives are easily exploitable and if these declaratives help to understand the influence of design solutions on minimizing suffering of users in usage situations.

\section{CONCLUSION}

The identification of non or poorly-covered usage segments, i.e. orphan usage scenarios, provides tangible insights for design solution providers attempting to become 
radically innovative need seekers. Consequently, they can target a more adequate market and better lead their design solutions to the market by knowing the number of elderly associated with a set of attributes. This is a way to correctly frame the problem to address the front-end of innovation. Forthcoming developments of the current research are studied in order to apply our model to other product families and encourage not only solution providers (in terms of precise specifications on usage scenarios), but also the national health system authorities to provide and finance data collections over the widespread case of falls among the elderly.

\section{ACKNOWLEDGMENT}

The authors gratefully acknowledge the support of the French Silver Valley and the meaningful helps of Pr. Francois Piette, the president of the scientific committee of the French Society of Technology for Autonomy and Gerontechnology (FSTAG).

\section{REFERENCES}

[1] Bentham, J., 2009, An Introduction to the Principles of Morals and Legislation, Dover Publications Inc.

[2] Pin Le Corre, S., Guilbert, P., and H., B., 2005, "Falls prevention of the elderly living at home. Francophone guidelines for good practices in community health."

[3] Stel, V. S., Smit, J. H., Pluijm, S. M., and Lips, P., 2004, "Consequences of falling in older men and women and risk factors for health service use and functional decline," Age Ageing, 33(1), pp. 58-65, http://www.ncbi.nlm.nih.gov/pubmed/14695865.

[4] DRIRE, 2009, "Issues and challenges of the gerontechnology industry in Ile-de-France," Paris, Available in French in: http://www.silvereco.fr/wp-content/driregerontechnologies.pdf.

[5] Clarkson, P. J., Buckle, P., Coleman, R., Stubbs, D., Ward, J., Jarrett, J., Lane, R., and Bound, J., 2004, "Design for patient safety: A review of the effectiveness of design in the UK health service," Journal of Engineering Design, 15(2), pp. 123-140, http://dx.doi.org/10.1080/09544820310001617711.

[6] Zimmer, B., Yannou, B., and Stal-Le Cardinal, J., 2012, "Proposal of a radical innovation project selection model based on proofs of value, innovation, and concept," International Design Conference - Design 2012Dubrovnik - Croatia, pp. 141-150.

[7] Dankelman, J., Grimbergen, C. A., and Stassen, H. G., 2005, Engineering for Patient Safety: The Clinically Driven Approach. Biomedial Instrumentation \& Technology, Lawrence Erlbaum Associates, New Jersey.

[8] Clarkson, J., and Coleman, R., 2010, "Inclusive design," Journal of Engineering Design, 21(2-3), pp. 127-129, http://www.tandfonline.com/doi/abs/10.1080/09544821003693689.

[9] Booz \& Co., 2012, "Making ideas work: The 2012 global innovation 1000," http://www.strategyand.pwc.com/media/uploads/Strategyand The-2012-GlobalInnovation-1000-Study.pdf.

[10] Ulrich, K., and Eppinger, S., 2000, Product design and development, Irwin/McGraw-Hill. 
[11] Allen, J. F., 2001, "On the Aggregation of Preferences in Engineering Design," Proc. ASME Design Engineering Technical Conferences.

[12] Messac A., Gupta S., and Akbulut, B., 1996, "Linear Physical Programming: A New Approach to Multiple Objective Optimization," Transactions on Operational Research, 8, pp. 39-59.

[13] Yannou, B., Chen, W., Yvars, P.-A., and Hoyle, C., 2013, "Set-based design by simulation of usage scenario coverage," Journal of Engineering Design, 24(8).

[14] Green, P. E., and Srinivasan, V., 1978, "Conjoint Analysis in Consumer Research: Issues and Outlook," Journal of Consumer Research, 5, pp. 103-123.

[15] Kumar, D., Hoyle, C., Chen, W., Wang, N., Gomez-Levi, G., and Koppelman, F., 2009, "A Hierarchical Choice Modeling Approach for Incorporating Customer Preferences in Vehicle Package Design," International Journal of Product Development, 8(3), pp. 228251.

[16] Hoyle, C., Chen, W., Ankenman, B., and Wang, N., 2009, "Optimal Experimental Design of Human Appraisals for Modeling Consumer Preferences in Engineering Design," Journal of Mechanical Design, 131(8).

[17] Hoyle, C., Chen, W., Wang, N., and Koppelman, F. S., 2010, "Integrated Bayesian Hierarchical Choice Modeling to Capture Heterogeneous Consumer Preferences in Engineering Design," Journal of Mechanical Design, 132(12), pp. 121010-121011, http://dx.doi.org/10.1115/1.4002972.

[18] He, L., Chen, W., Hoyle, C., and Yannou, B., 2012, "Choice modeling for usuage contextbased design," Journal of Mechanical Design, 134(3).

[19] Wang, J., and Yannou, B., 2010, "A market segmentation process based on usage context," International conference on Kansei engineering and emotion research (KEER)Paris.

[20] Telenko, C., 2012, "Probabilistic Graphical Modeling as a Use Stage Inventory Method for Environmentally Conscious Design," PhD. Thesis, The University of Texas at Austin.

[21] Telenko, C., and Seepersad, C., "Scoping usage contexts and scenarios in eco-design," Proc. ASME 2014 International Design Engineering Technical Conferences \& Computers and Information in Engineering Conference IDETC/CIE 2014.

[22] Wang, J., Yannou, B., Alizon, F., and Yvars, P.-A., 2013, "A usage coverage-based approach for assessing product family design," Engineering With Computers, 29(4), pp. 449-465.

[23] Green, P. E., and Krieger, A. M., 1991, "Segmenting markets with conjoint analysis," Journal of Marketing, 55(4), pp. 20-31.

[24] Muller, M. J., and Kuhn, S., 1993, "Participatory design," Journal of communications of the ACM, 36(6), pp. 24-28.

[25] Beyer, H., and Holtzblatt, K., 1998, Contextual Design: Defining Customer-Centered Systems, Kaufmann Publishers, San Francisco.

[26] Belk, R., 1974, "An exploratory assessment of situational effects in buyer behavior," Journal of Marketing Research, 11, pp. 156-163. 
[27] Cooper, A., 2004, The Inmates are Running the Asylum: Why High Tech Products Drive Us Crazy and How to Restore the Sanity, Sams - Pearson Education.

[28] Philips, D., 1996, "Anticipating the future: The role of consumption visions in consumer behavior," MacInnis D.J., 23(1), pp. 70-75.

[29] Hoffmann, J., Mathieu, J.-P., Roehrich, G., and Mallein, P., 2008, "Evaluating design as a system of representations: the moderating role of representation towards the use of new technologies," International Product Development Management Conference,Hamburg, Germany.

[30] Hoffmann J., Roehrich G., and J.-P., M., 2006, "The role of usage and usage intention anticipations in a new product appraisal," International Conference 29 of the French Marketing Association,Nantes, France.

[31] Wang, J., 2012, "A usage coverage based approach for assessing product family design Une méthode d'évaluation de la conception d'une famille de produits basée sur le modèle de couverture d'usages," Phd Thesis, Ecole Centrale Paris.

[32] Petrov, V., 2002, "The laws of system evolutions," The TRIZ Journal, http://www.trizjournal.com/laws-system-evolution/.

[33] Savransky, S. D., 2000, Engineering of creativity - Introduction to TRIZ Methodology of Inventive Problem Solving, Boca Raton.

[34] Gibson, M., Andres, R., Isaacs, B., Radebaugh, T., and Worm-Peterson, J., 1987, "The prevention of falls in later life," Kellogg International Work Group on the Prevention of Falls in the Elderly,Dan Med Bull., pp. 1-24.

[35] Medica Center of World Health Organization (WHO), 2007, "Global report on falls prevention in older age," http://www.who.int/ageing/publications/Falls prevention7March.pdf.

[36] Robert-Bobee, I., 2006, "Population trends in France - looking ahead to 2050 - An increasing and ageing population," Insee Première, http://www.insee.fr/en/themes/document.asp?ref id=IP1089.

[37] Blake, A. J., Morgan, K., Bendall, M. J., Dallosso, H., Ebrahim, S. B., Arie, T. H., Fentem, P. H., and Bassey, E. J., 1988, "Falls by elderly people at home: prevalence and associated factors," Age Ageing, 17(6), pp. 365-372, http://www.ncbi.nlm.nih.gov/pubmed/3266440.

[38] Campbell, A. J., Reinken, J., Allan, B. C., and Martinez, G. S., 1981, "Falls in old age: a study of frequency and related clinical factors," Age Ageing, 10(4), pp. 264-270, http://www.ncbi.nlm.nih.gov/pubmed/7337066.

[39] Prudham, D., and Evans, J. G., 1981, "Factors associated with falls in the elderly: a community study," Age Ageing, 10(3), pp. 141-146, http://www.ncbi.nlm.nih.gov/pubmed/7270321.

[40] DREEES, 2011, "French population health profile - 2011 Report (L'état de santé de la population en France - Rapport 2011)," http://www.drees.sante.gouv.fr/IMG/pdf/esp2011 83 groupes pop obj99.pdf.

[41] French epidemiology centre on medical causes of death (CepiDc ), 2013, Number of deaths because of an accidental fall, Paris, France. 
[42] Sullivan, D. F., 1971, "A single index of mortality and morbidity," HSMHA Health Rep, 86(4), pp. 347-354, http://www.ncbi.nlm.nih.gov/pubmed/5554262.

[43] Institute for research and information for health economics (IRDES), 2011, Health data bases (Eco-Santé), Paris, France.

[44] Skelton, D., and Dinan, S., 1999, "Exercise for falls management: rationale for an exercise program aimed at reducing postural instability," Physiological Theory and Practice, 15(2), pp. 105-120.

[45] Belk, R., 1975, "Situational variables and consumer behavior," Journal of Consumer Research, 2, pp. 157-164.

[46] Rubenstein, L. Z., 2006, "Falls in older people: epidemiology, risk factors and strategies for prevention," Age and Ageing, 35(suppl 2), pp. ii37-ii41, http://ageing.oxfordjournals.org/content/35/suppl_2/ii37.abstract.

[47] Tinetti, M. E., 1987, "Factors associated with serious injury during falls by ambulatory nursing home residents," J Am Geriatr Soc, 35(7), pp. 644-648, http://www.ncbi.nlm.nih.gov/pubmed/3584769.

[48] Bekhradi, A., Yannou, B., Farel, R., and Zimmer, B., 2013, "Selection and validation of variables and consequences for building a usage scenarios space for the case of fall among the elderly, Technical document," http://www.lgi.ecp.fr/uploads/Publications/Usage Scenario.

[49] Ricard C, T. B., 2007, "Several hundreds of thousands falls in elderly people each year in France," BEH thematique, 37-38, pp. 318-322.

[50] Campbell, A. J., Borrie, M. J., Spears, G. F., Jackson, S. L., Brown, J. S., and Fitzgerald, J. L., 1990, "Circumstances and consequences of falls experienced by a community population 70 years and over during a prospective study," Age Ageing, 19(2), pp. 136-141, http://www.ncbi.nlm.nih.gov/pubmed/2337010.

[51] Aschkenasy, M. T., and Rothenhaus, T. C., 2006, "Trauma and falls in the elderly," Emergency medicine clinics of North America, 24(2), pp. 413-432, vii, http://www.ncbi.nlm.nih.gov/pubmed/16584964.

[52] Karandikar, J., McLeay, T., Turner, S., and Schmitz, T., "Remaining useful tool life predictions in turning using bayesian inference," Proc. ASME 2013 International Manufacturing Science and Engineering Conference collocated with the 41st North American Manufacturing Research Conference.

[53] Abbas, A. E., Hazelrigg, G., and Al-Kindi, M., "Bayesian Inference for the Demand of Engineering Products," Proc. ASME 2012 International Design Engineering Technical Conferences and Computers and Information in Engineering Conference.

[54] Awedikian, R., and Yannou, B., 2012, "A practical model-based statistical approach for generating functional test cases: application in the automotive industry," Software Testing, Verification and Reliability, pp. n/a-n/a, http://dx.doi.org/10.1002/stvr.1479.

[55] Robitaille, Y., and Gagné, M., 2007, "Hospitalizations because of falls among the elderly (Les hospitalisations pour chute chez les adultes âgés)," Bulletin épidémiologique hebdomadaire, (37-38), http://www.invs.sante.fr/beh/2007/37 38/beh_ 37 38_2007.pdf. 
[56] Keyes, M. J., 1996, "Hip inflatable protection device," Google Patents.

[57] Pólya, G., 1945, How to Solve It: A New Aspect of Mathematical Method, Princeton, NJ: Princeton University Press.

[58] Yannou, B., Farel, R., and Cluzel, F., 2015, "The DSM value bucket tool," to be presented at ICoRD'15, International Conference on Research into Design Banglore, India.

[59] Kim W.C., and Mauborgne, R., 2005, Blue Ocean Strategy: How to Create Uncontested Market Space and Make Competition Irrelevant, Harvard Business Press. 